\title{
Factors influencing health self-management in adherence to care and treatment among the recipients of liver transplantation
}

This article was published in the following Dove Press journal:

Patient Preference and Adherence

\author{
Malihe Sadat Moayed' \\ Abbas Ebadi² \\ Masoud Khodaveisi ${ }^{3}$ \\ Mohssen Nassiri Toosi ${ }^{4}$ \\ Ali Reza Soltanian ${ }^{5}$ \\ Mahnaz Khatiban ${ }^{6}$ \\ 'Department of Medical-Surgical \\ Nursing, School of Nursing and \\ Midwifery, Hamadan University of \\ Medical Sciences, Hamadan, Iran; \\ ${ }^{2}$ Nursing Education, Behavioral \\ Sciences Research Center, Life \\ Style Institute, Faculty of Nursing, \\ Baqiyatallah University of Medical \\ Sciences, Tehran, Iran; ${ }^{3}$ Chronic \\ Diseases (Home Care) Research \\ Center, Community Health Nursing \\ Department, Hamadan University \\ of Medical Sciences, Hamadan, Iran; \\ ${ }^{4}$ Internal Medicine, Hepatologist, \\ Liver Transplantation Research \\ Center, Tehran University of Medical \\ Sciences, Tehran, Iran; ${ }^{5}$ Modeling of \\ Noncommunicable Diseases Research \\ Center, School of Public Health, \\ Hamadan University of Medical \\ Sciences, Hamadan, Iran; ${ }^{6}$ Mother and \\ Child Care Research Center, Medical- \\ Surgical Nursing Department, School \\ of Nursing and Midwifery, Hamadan \\ University of Medical Sciences, \\ Hamadan, Iran
}

Correspondence: Mahnaz Khatiban Mother and Child Care Research Center, Medical-Surgical Nursing Department, School of Nursing and Midwifery, Hamadan University of Medical Sciences, Fahmideh Blvd, Hamadan, Iran

Tel +989188115956

Fax +98 8138380447

Email mahnaz.khatiban@gmail.com

\begin{abstract}
Introduction: Liver transplantation is the global treatment of end-stage liver diseases. Since the patients' survival rate has been improved, the patient may experience reductions in physical, cognitive, and psychosocial functions after liver transplantation influencing their adherence to care and treatment. The transplant survival is complex and patients' adherence to care and treatment should be considered when health care providers make decisions regarding treatment. This qualitative study aimed to explore factors influencing health self-management in adherence to care and treatment among the recipients of care and treatment.
\end{abstract}

Methods: In this study, 23 interview sessions were carried out with a total 18 patients, 2 family members and 3 transplantation team members from May to November 2017. The patients were selected using the purposive method from both genders, with a various age range and initial diseases leading to liver transplantation, and time passed from liver transplantation. A semistructured interview guide was developed based on literature review and pilot interviews. The participants were asked to describe their experiences of self-management behaviors in adherence to treatment and care. The data were analyzed using a conventional content analysis method and managing via the MAXQDA-10 software.

Results: Two themes were developed during data analysis as "self-regulation" and "self-care". "Self-regulation" consisted of "intentionally changing", "positively thinking", "information seeking", "problem-solving", "past knowledge transferring", and "self-controlling". "Self-care" had three sub-themes "shift to independence", "vigilance", and "self-care support".

Conclusion: The participants perceived the health self-management in adherence to care as a set of factors related to "self-regulation" and "self-care" behaviors. "Self-regulation" is required to create a balance in life. Also, "self-care" efforts can help with maintaining and improving patients' health.

Keywords: liver transplantation, qualitative research, self-management, self-care, self-regulation, adherence, recipient, compliance, treatment

\section{Introduction}

Liver transplantation is a well-established treatment for patients with acute or chronic end-stage liver dysfunction. ${ }^{1-3}$ While it is not considered a final cure, it can provide remedy to overcome an immediate threat of liver dysfunction. Nevertheless, it creates a chronic condition and necessitates specialized and continuous care to preserve the transplanted organ. ${ }^{4}$ The treatment success depends on an active cooperation of the patients and adherence to the therapeutic regime and care. ${ }^{5}$ Non-adherence to the treatment process can adversely affect the transplanted organ function and survival. ${ }^{6}$ Non-adherence to immunosuppressive medications has been reported in 
$73 \%$ of patients within the first 6 months $^{7}$ and $22 \%-62 \%$ within 3 years after liver transplantation. ${ }^{8}$ Germani et al ${ }^{5}$ and Stilley et $\mathrm{al}^{7}$ found that up to $47 \%$ of patients did not show up in scheduled medical appointments. Less-than-optimal adherence was associated with readmissions to the hospitals in $50 \%$ of patients with liver transplantation and increased health care costs up to $\$ 100$ billion in the US and in many countries. ${ }^{3,6,9}$

Patients with liver transplantation need to adhere to a complex therapeutic regimen after surgery including taking medicines to prevent organ rejection, ${ }^{10}$ preventive health care to prevent the disease progression, ${ }^{11}$ and engaging in a healthy lifestyle to promote normal functions. ${ }^{12}$ All treatment modalities and recommendations' for adherence to care and treatment are essential for recovery and achieving treatment goals. . $^{5,13,14}$

Adherence is demanding and is influenced by factors related to both patients and treatment. Patient-related factors are personal beliefs, values about the health condition and treatment, personality traits, socioeconomic status, overall health and functioning level. Treatment-related factors often represent the number and dose of medications, the experience of side effects, ${ }^{15}$ and physical and cognitive symptoms as a result of treatment. ${ }^{16}$

The philosophy of care for most chronic diseases has migrated from health care provider-centeredness to patient self-management. ${ }^{17}$ Self-management is considered an add-on to adherence and an efficient part of patient care. It is consisted of activities which chronic patients must perform to survive with their conditions and follow their life wishes. ${ }^{18}$

Beckmann et al demonstrated that self-management is a cornerstone of care for patients with liver transplantation. ${ }^{19}$ Schmid-Mohler et al explained the self-management concept in kidney transplantation..$^{20}$ As the central aim of good health care, patients' self-management dimensions should be understood and health care culture and finance should be changed. ${ }^{21}$

When a decision is made on liver transplantation, it is the responsibilities of the transplantation team to ensure health self-management by the patient. Nursing care has always played an important role in the provision of care to patients and their family members. It has been influenced by different factors including knowledge, awareness, and skill of transplantation care. Nurses, as the members of the transplantation team, need to know which factors affect patients' adherence to liver transplantation care and treatment. Knowledge of these factors is essential to design supportive nursing interventions.
The complexity of the transplantation process, shortened the hospitalization period, increase of survival, and improvement of the quality of life have increased the need for the quality of health care by nurses at the hospital and society.

Liver transplantation has been performed in Iran for over 20 years. ${ }^{22}$ Liver transplantation care after the surgery consists of hospitalization in the ICU for several days and transfer to the transplantation ward, staying for about 2 weeks. Specialized nurses provide appropriate care and education to patients and their relatives until they are discharged from the hospital. Education consists of direct patient education and delivery of information on medicines, diet, exercise program, preventions, self-assessment, family planning and medical follow-up. Pamphlets are given to the patients at discharge.

The usual immunosuppressive regimen is a combination of calcineurin inhibitor tacrolimus (Prograf ${ }^{\circledR}$ ) plus mycophenolate mofetil $\left(\mathrm{Cellcept}^{\circledR}\right)$ and prednisolone. Prednisolone is tapered off after 4-6 months, except in autoimmune liver diseases.

The growing number of patients with liver transplantation, difficulties and challenges such as insufficient donors and high health care costs has increased the demand for a clear description of health self-management in patients with liver transplantation. The use of a qualitative approach is necessary to gain a deeper understanding of patients' perspectives on individual factors related to health management and adherence to care and treatment. Therefore, the aim of this study was to explore the definition of health self-management factors affecting adherence to care and treatment in patients with liver transplant.

\section{Methods}

This qualitative study used an inductive conventional approach. ${ }^{23}$ A purposive sampling with maximum variation was performed and 18 patients with liver transplant were selected. Also, a snowball strategy was used to select potential informants including 2 physicians and a nurse coordinator of the transplantation team and 2 patients' family members from May to November 2017. Inclusion criteria for the participants were: more than 3 months passed from liver transplantation, having no disabilities, more than 18 years old. Variation in sampling was achieved in the participants' age, gender, underlying liver disease leading to transplantation, and time passed from transplantation (Table 1A-C).

Face-to-face interview sessions were held by first author (MM) in a consultation room at the Liver Transplantation Clinic affiliated with the Liver Research Center of Tehran 
Table I Demographic characteristics of participants

\begin{tabular}{|c|c|c|c|c|c|c|c|c|c|}
\hline Participants & Sex & Age & $\begin{array}{l}\text { Marital } \\
\text { status }\end{array}$ & $\begin{array}{l}\text { Time of liver } \\
\text { transplant }\end{array}$ & \multicolumn{2}{|c|}{ Education } & $\begin{array}{l}\text { Cause of } \\
\text { transplantation }\end{array}$ & Job before & \begin{tabular}{|l|} 
Interview \\
duration \\
minutes
\end{tabular} \\
\hline I & Male & 36 & Married & 10.2016 & \multicolumn{2}{|c|}{$\begin{array}{l}\text { Bachelor of } \\
\text { mathematics }\end{array}$} & Hepatitis C & Prison officer & 72 \\
\hline 2 & Female & 44 & Divorced & 12.2014 & \multicolumn{2}{|l|}{ Diploma } & Hepatitis B & Employee & 62 \\
\hline 3 & Male & 45 & Married & 5.2013 & \multicolumn{2}{|c|}{ Software engineer } & Autoimmune & Company marketer & 60 \\
\hline 4 & Male & 56 & Married & 8.2014 & \multicolumn{2}{|c|}{ Under diploma } & Fatty Liver & Agency driver & 47 \\
\hline 5 & Male & 36 & Married & 12.2016 & \multicolumn{2}{|l|}{ Diploma } & Budd-Chari syndrome & Employer & 48 \\
\hline 6 & Male & 56 & Married & 10.2015 & \multicolumn{2}{|l|}{ Diploma } & Alcoholism & Self-employer & 58 \\
\hline 7 & Male & 66 & Married & 1.2014 & \multicolumn{2}{|c|}{ Elementary fifth } & Hepatitis B & Builder & 30 \\
\hline 8 & Male & 63 & Married & 3.2013 & \multicolumn{2}{|l|}{ Diploma } & Cryptogenic cirrhosis & $\begin{array}{l}\text { Municipality } \\
\text { employee retired }\end{array}$ & 53 \\
\hline 9 & Female & 58 & Married & 12.2015 & \multicolumn{2}{|l|}{ Diploma } & Fatty liver & Housewife & 64 \\
\hline 10 & Female & 46 & Married & 4.2014 & Bachelor & of sociology & Autoimmune & Housewife & 60 \\
\hline II & Female & 24 & Single & 1.2012 & $\begin{array}{l}\text { Bachelor } \\
\text { Persian II }\end{array}$ & $\begin{array}{l}\text { of law and } \\
\text { terature }\end{array}$ & Cryptogenic cirrhosis & Sports coach & 25 \\
\hline 12 & Female & 47 & Married & 6.2010 & Associat & degree & Myelofibrosis \& PSC & School clerk & 62 \\
\hline 13 & Male & 55 & Married & 10.2016 & Illiterate & & Hepatitis C & Aviculture retired & 20 \\
\hline 14 & Female & 53 & Divorced & 10.2006 & Bachelor & of English & Autoimmune & Air agency employer & 53 \\
\hline 15 & Male & 36 & Single & 9.2015 & Elementa & ry fifth & Alcoholism \& hepatitis C & Chef & 44 \\
\hline 16 & Male & 60 & Married & 3.2012 & Diploma & & Fatty liver & $\begin{array}{l}\text { Metal structures, } \\
\text { Retired }\end{array}$ & 41 \\
\hline 17 & Male & 49 & Married & 10.2014 & Master's & degree & PSC & University master & 40 \\
\hline 18 & Male & 45 & Married & 1.2017 & Low liter & acy & Hepatitis B & Laundry worker & 25 \\
\hline Section A: li & ver trans & plant $r$ & recipient & & & & & & \\
\hline Participant & $\begin{array}{l}\text { Relativ } \\
\text { the tra } \\
\text { recipie }\end{array}$ & $\begin{array}{l}\text { e to } \\
\text { insplan } \\
\text { ant }\end{array}$ & $\begin{array}{l}\text { Caus } \\
\text { trans }\end{array}$ & $\begin{array}{l}\text { of } \\
\text { lantation }\end{array}$ & Job & \begin{tabular}{|l|} 
Duration \\
of care \\
(month)
\end{tabular} & Age & Sex & $\begin{array}{l}\text { Interview } \\
\text { duration } \\
\text { minutes }\end{array}$ \\
\hline 19 & Spouse & & Fatty I & & Retired & 12 & 65 & Male & 38 \\
\hline 20 & Spouse & & $\begin{array}{l}\text { Intrav } \\
\text { addict }\end{array}$ & $\begin{array}{l}\text { nous drug } \\
\text { on hepatitis }\end{array}$ & Housewife & 48 & 41 & Female & 40 \\
\hline Section B: li & ver trans & plant $r$ & recipient' & amily & & & & & \\
\hline Participant & Sex & & Educ & tion & Age & $\begin{array}{l}\text { Marital } \\
\text { status }\end{array}$ & \begin{tabular}{|l} 
Transplant team' \\
membership \\
duration (year)
\end{tabular} & Specialist & $\begin{array}{l}\text { Interview } \\
\text { duration } \\
\text { minutes }\end{array}$ \\
\hline 21 & Female & & MD & & 40 & Married & 10 & Dost of coordinator & 44 \\
\hline 22 & Female & & $\begin{array}{l}M D \text { in } \\
\text { diseas }\end{array}$ & $\begin{array}{l}\text { ectious } \\
\text { specialist }\end{array}$ & 53 & Married & 11 & $\begin{array}{l}\text { Chief member of } \\
\text { ransplant commission }\end{array}$ & 45 \\
\hline 23 & Female & & $\mathrm{MSC}$ & ursing & 48 & Married & 16 & Post of coordinator & 54 \\
\hline
\end{tabular}

Abbreviation: PSC, Primary Sclerosing cholangitis.

University of Medical Sciences, Tehran, Iran. The interviews' duration lasted between 20 and 70 minutes. A semi-structured interview guide was developed based on related literature and pilot interviews. The main focus of the interviews was to explore the underlying health self-management behaviors in adherence to care and treatment. The interviews began with a general question and were narrowed down to the participants' performance and activity patterns of daily living after transplantation and were followed by branching questions. First, they were asked to describe their current daily living activities and behaviors related to treatment and care programs considering important changes they have made in their previous behaviors, and how they dealt with changes and also motivations for seeking care. The patients explained treatment experiences and gave details of their participation in the treatment and care plans to maintain and improve their 
health after liver transplantation. Nonverbal responses of the participants are used for designing subsequent questions. The interviews were discontinued when data saturation was achieved after 20 interviews. However, three interviews were done to be sure that no new code and category were extracted. None of the patients declined participation.

\section{Data analysis}

The interviews were transcribed verbatim. The MAXQDA 10 software was used to manage data. The conventional content analysis approach was used for data analysis with three steps of preparation, organization, and reporting phases. ${ }^{23}$ This approach made it possible to examine a diversity of statements and produced meaningful units regarding liver transplantation and adherence to care and treatment. In the preparation phase, each transcription was reviewed several times to be immersed in data. Meaningful units were extracted from the participants' statements and line-by-line coding was performed. The field notes, the manifest and latent contents of the interviews were analyzed, including silence or participatory interruption, smacking, laughter, and other reactions. Categories were generated during repeated discussions between the researchers. In the organization phase, some categories with similar meaning were gathered with other and were classified to main categories. Main themes were developed and relationships between themes and codes were reviewed and discussed by the researchers until an agreement was reached. A pattern of the participants' experiences of health self-management factors with liver transplantation and how this was related to adherence to care and treatment was developed.

\section{Trustworthiness}

The researcher was a female nurse instructor that lived for five years with a family member who had undergone liver transplantation and were presented constantly in the liver transplant clinic for 24 months. Also she passed a qualitative methodological course.

To develop credibility of findings, a diverse sample of patients and data triangulation were used; the transcriptions were read repeatedly and compared with the audiotaped interviews, as well as interviewee transcript review to confirm the accuracy of data. Appropriate semantic units were chosen to explain how categories and themes were formed. The participant quotes were carefully studied to differentiate categories. The interviews were recorded and extensively reviewed by member and peer checking to ensure the rigor of the study. Qualitative research experts supervised the whole data collection and analysis process. For transferability, a more detailed description of the methods used in the study was provided.

\section{Ethical considerations}

The authors declare that this study was conducted in accordance with the ethics declaration of Helsinki 1995, revised 2001. The study was approved by the Research Ethics Committee and Vice-chancellor in Research and Technology (REC. IR.UMSHA.1396.109) at Hamadan University of Medical Sciences, Iran. All participants were informed of the design and purpose of the study and the voluntary nature of their participation. Written informed consent was signed by volunteer participants. Additionally, each participant could withdraw at any time without any consequence.

\section{Results}

A total of 23 participants took part in the study consisting of 18 patients with liver transplantation, 3 transplantation team members and 2 patients' family members. The patients were 12 men and 6 women, aged 24-66 years with a mean age $48.61, \mathrm{SD}=10.94$ years. The mean time of the post-transplantation period was $31.2, \mathrm{SD}=26.9$ months with a range from 4-120 months. The mean duration of membership in the transplant team was $148, \mathrm{SD}=38.5$ months. The mean duration of the post-transplant family caregivers was 30 months (Table 1). During the analysis, 611 codes and nine subcategories were developed and two categories were explored. Health self-management was derived from two categories. Figure 1 depicts the main categories and subcategories.

Health self-management reflected factors influencing the patients' cognitive, mental, and behavioral ability to identify disease-related symptoms, seek treatment, and to identify physical, psychological, and social changes. The aim of health self-management is to survive the transplanted organs and consequently improve patient health. The following two main categories were developed regarding health self-management and adherence to treatment and care after liver transplantation: "self-regulation" related factor and "self-care" related factor. Each theme is explained below using the patient's direct quotations.

\section{Self-regulation related factors}

The patients perceived that the liver transplantation surgery often involved challenging changes in their everyday life. They found themselves confronted with constant changes in their physical appearance, mental and psychosocial aspects 


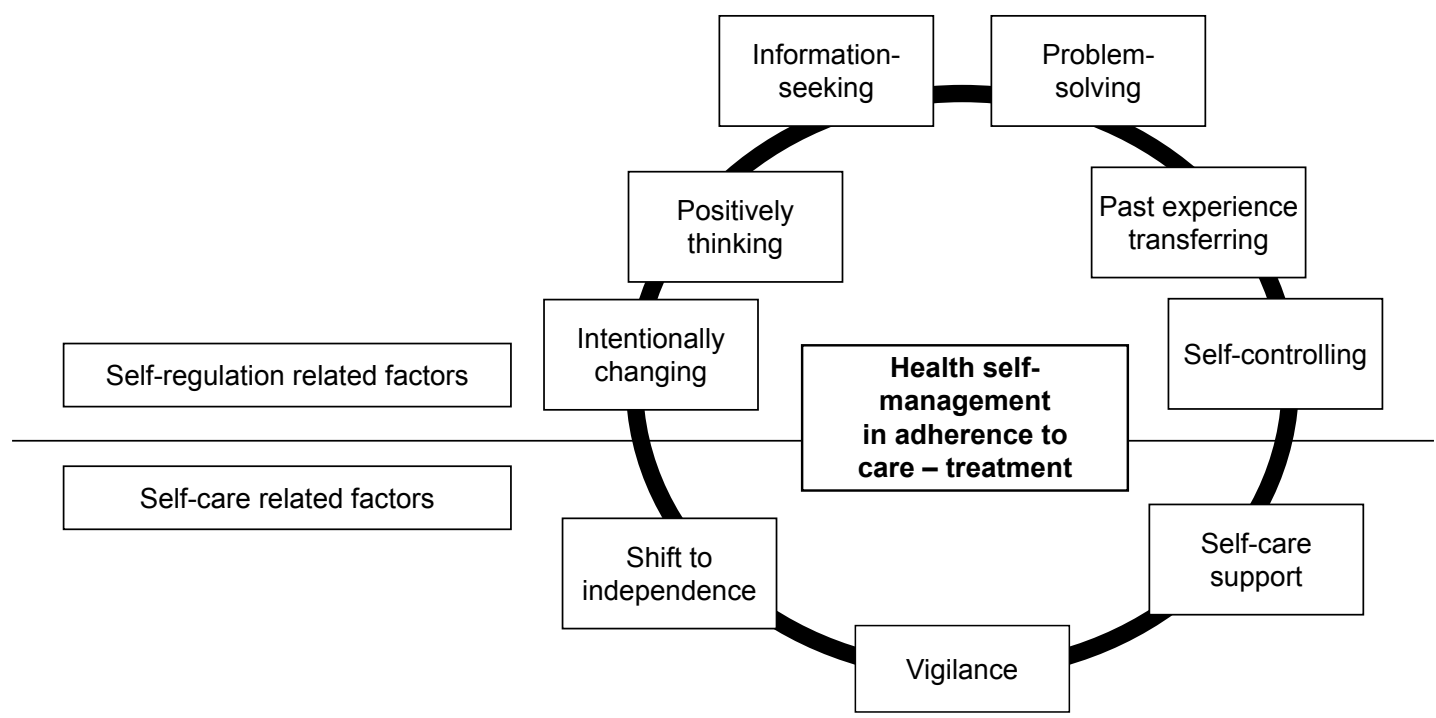

Figure I Self-regulation and self-care related factors influencing health self-management in adherence to care and treatment among the recipients of liver transplantation.

of life. Adherence to care and treatment disrupted the patients' entire life, so patients' efforts to adapt to these changes were very important. These factors were self-regulation behaviors and allowed the patients to deal with care and treatment programs. Self-regulating behaviors included "intentional changing", "positively thinking", "information-seeking", "problem-solving", "past experience transferring", and "self-controlling".

\section{Intentionally changing}

Intentionally changing was an effort for effective selfregulation. It meant patients' efforts to accept daily life changes and consequently adjust with them. Changing by intention enabled the patients to develop self-management and continued their treatment and care.

A female liver recipient (36 months post-transplant surgery (months post-transplant [mpt]) participant (P) 10) responded to the question: How have you been dealing with the daily life changes to continue your treatment and care?

Acceptance and tolerance, although acceptance plays a more important role in care .... I needed a change; it's not easy to change my routines, I made changes in myself that I know them better than anyone ... [I know] what is going on in me....

... I know that a revolution [huge changes] took place in me [health].... What was it? Was it a revolution that took place [in my whole life]? Indeed, I said that I have to change. I become another person. I wanted to change my name. I was that kind of person. I decided to change, I am no longer the same person. I just understood what life was.... Just understood how to treat the family. Maybe I was mentally violent, but I am not anymore. I became more humble. (20 mpt P 6)

\section{Positive thinking}

Positive thinking was a significant factor in self-regulation of daily life changes. Considering that being alive was a gift and belief that overcoming the disease-related problems motivated the patients to comply with the care and treatment plan.

A female patient (16 mpt, P 9) explained:

I have very high [positive] enthusiasm, I can put my sewing machine back on the dining table and I [am able to] make everything that my children or grandchildren or myself want [similar to when I was healthy], I am very enthusiastic [to survive] and I thank God a thousand times every day that I am still alive ... when we go to visit friends and relatives, they all thank God as soon as they see me healthy and always say that I look so much better ... that really motivates me to stick to my treatment plan....

\section{Information-seeking}

Information-seeking was the patients' efforts to improve their health knowledge and performance to regulate their daily life changes. Self-regulated patients were not passive and actively sought information when needed. The patients perceived that they should seek knowledge by asking questions from health care professionals and survivors, searching on the internet, paying attention to the social media, and practical involvement to encounter changes. 
A male patient (48 mpt, P 3) stated:

I noticed that I was asking a lot of questions regarding diet [from the health care team], because I thought I needed to ask. I should come into contact with them [the health care team].... I realized that my family members did not know any more than myself about my diet, and they always suggested that I would learn by practical experiences, what is good for me and what is not.... I learn a lot about what I can do to protect my liver every time I saw them [previous patients], they are more experienced than me....

\section{Problem-solving}

A patient with liver transplantation is constantly surrounded by the need to react to health care problems. Problem-solving is related to efforts to identify problems, barriers, and opportunities and develop and implement actual solutions. Problem-solving was required for the attachment to care and treatment during the follow-up periods.

... The transplantation clinic here is next to the infectious diseases clinic [temporarily, because of the structure renovation], which is absolutely wrong and should be paid attention by authorities. Whenever I come here, I try not to stay here for long and I always come and go ... imagine someone is not careful about it, imagine what would happen, anything could happen.... (36 mpt, P 4)

\section{Past experience transferring}

Since the most common causes of liver diseases are chronic and liver fails over months to years, patients can have valuable experiences in self-management. Past experiences of transition were used by patients to transit to the new health situation. The patients who could transfer their previous knowledge and skills in the post-transplantation period were more successful in adherence to care and treatment. If the patient did not transfer what he/she learnt to the similar new situation, self-regulation would be much slower and less efficient:

... I had a strict diet before my [liver] transplantation and I continued that diet after the transplant, because I had some useful experiences about how it can increase my health ... others [patients] might be in danger, if they did not do it.... (Male patient, 48 mpt, P 3)

.... I always know how to comply with my regimen [diet]; if I get invited to a party that I know the food will be oily, [unhealthy food], I tell my family [that the food is not good for me] and I have something at home and inform the hosts that I would not eat there ..., because I know how [experience] it is going to be.... (Male patient, 20 mpt, P 6)

\section{Self-controlling}

Self-controlling was the patient's efforts to regulate his/her thoughts, emotions and behaviors to face fears and temptations. They had to have some kind of control on their fears and stress as well as their habits to stay loyal to their care and treatment process. Stress control was a recurring ability that was emphasized by many respondents.

A female patient (120 mpt, P 14) explained:

I went to the pathology lab yesterday.... I am always worried about the result, what can it be? What is the result? Because we [patient with liver transplantation] are always at risk [rejection of liver or cancer]. I am very careful to control any mental or psychological stress....

Control over the temptation to reuse drugs and alcohol was another factor among addicted patients to adhere to care and treatment.

The wife of the drug-addict patient said:

... if anyone talks to him, they would not believe that he has ever smoked, and this is because he reads a lot about it at work and watches all programs on TV every night, on the Health Channel [an Iranian TV channel], for example, those about addiction.... (48-month duration of caregiving $\mathrm{P}$ 20)

A male patient with 40 years alcoholism said:

I do not get along with them [alcoholic people], I do not communicate with them. I try hard to keep myself away from them, for example, I play volleyball. (20 mpt, P 6)

Lack of control over desires led to non-adherence to care and treatment.... Some patients have habits that are difficult to quit, despite that patients have promised to quite them before the surgery. There was some patients [liver recipients] interested in flowers and plants or loved pets. For example, one [male patient] was holding the pigeons at home. [After the surgery], he could not give up that due to his dependencies [to pigeons], which led to non-adherence behaviors.... (Coordinator nurse in the transplantation 5 team $\mathrm{P} 23$ )

\section{Self-care related factors}

Self-care related factors included any action initiated and applied by the patients, families, health professionals, and community to maintain and improve patient's health. They were perceived important in the health self-management of 
the patients to adherence to care and treatment. Self-care related factors were consisted of categories of "shift to independence", "vigilance", and "self-care support".

\section{Shift to independence}

Shift to independence assisted the patients and prepared and enabled them to move toward greater self-care and health self-management.

As a female recipient (36 mpt, P 10) stated:

... no matter how much dependence, it is the expectation, and this is what in turn creates more expectation.... I say everyone in this world is just the one's own self, and just that, no matter if you have $10 \mathrm{kids}$ or a dozen parents or a husband; you are all alone on your own. I think we should learn to stand on our own feet, relying only on ourselves. It is great, if they help you, but what if they do not? What if you go on with their support and later look back and see none? Nobody is there for you!

Or I have an 18-year old daughter, we are friends, and I have always been his inspiration. I made her champion in Asia [the Asian championship]. We planned this [success] together, and she was with me all along. However, I told her that she needed to go after her life, her studies and that I could take care of myself.... (Male patient, 4 mpt, P 18)

\section{Vigilance}

Vigilance was the patient and their families' ability or state of keeping careful watch for possible problems or difficulties. It could save the liver and patient's life. A patient or family with the high level of vigilance could perform self-care through "sensitivity to signs and symptoms" and "monitoring cues" of threats and dangers.

The wife of patient stated:

... given his situation [high body temperature, chills, and nausea], we were worried and called the health care clinic, and the coordinator said we should urgently take him to the clinic, and we did so.... (48-month duration of caregiving, P 20)

A male patient (5 mpt.p.1) replied:

... Two days after I was discharged from the hospital, I had severe fever and chills at midnight ... my wife took my temperature, which was $39.5 \mathrm{C}$; she put wet sponges on my head to cool me down.... I called my doctor and explained the situation, and she urged me to go back to the hospital to get admitted....

Monitoring the cues was another part of vigilance, which persuaded self-care among the patient. If the patient were vigilance to monitoring the liver function through laboratory and paraclinical studies and regular follow-up visits, they would adhere to care and treatment protocols:

... If patients and their families pay attention to the significance of liver examinations, they follow-up regular tests of liver function and sonography at 1, 6, and 12 months post-surgery.... (The coordinator physician of the transplantation team, P 22)

\section{Self-care support}

Self-care support is efforts by patients, family members, colleagues, and professionals to support self-care intervention to meet their needs in short- and long-term conditions. Self-care support helped the patients to make self-care and consequently follow care and treatment activities. Providing patients with information and consultation based on patients' experiences and conditions provided support to the participants. Self-care supports were "support of the incision wound", "preventive health care", "dietary supplements" and "timely taking medications".

For support of the incision wound, the transplantation team physician coordinator explained:

... We should tell them [liver transplantation] to wear this abdominal elastic [binder] support for up to three months after the surgery so they the risk of an incisional hernia is reduced and the patient experienced less pain, because the abdomen becomes stiffer and patient feel less pressure.... (P 21)

The preventive health care by the patients were "vaccination", "sexual and reproductive care", "weight control", and "personal hygiene and food safety".

Physicians supported the patients by vaccinating them against diseases. A physician in the transplantation team said:

Specifically hepatitis A vaccine is mentioned; if they have not received it before transplantation and if they have a negative hepatitis A serology test, they should get the shot.... (P 22)

For supporting patients' survival, they are strictly advised to comply with family planning and use the male condom. A nurse in the transplantation team explained:

A woman who received liver transplantation, [because] she wanted to stay alive to have a child, as soon as possible ... to save her marriage.... [She] was not able to wait for another 6 months [the female patients were advised to 
prevent pregnancy for at least 2 years after transplantation], and finally lost her life...

Patients supported themselves through efforts to prevent gaining weight and get obese, as the common side effects of immunosuppressive medications. They believed that they should try to engage in athletic activities despite their limitations and to change their lifestyle. A female respondent (40 mpt, P 10) explained:

It [prevention of gaining weight] is the basis of care, I am very careful, because I have gained weight, because of corticosteroid medications, it increased my appetite. I have controlled my eating habits, and I have decreased my meal portions to $2-3$ spoons every night with low salt and low fat. Diet is extremely important for such a patient....

Another male respondent (48 mpt, P 3) stated:

I am trying to increase the duration of my routine exercise, three to four times a week, for an hour or hour and a half each time. I do yoga and other types of exercises....

The patients had fewer immune defenses, so they would be influenced by diseases. So, the patients should be supported in adherence to the personal, interpersonal, and environmental hygiene and food safety. A female patient (60 mpt, P 11) said:

I avoid kissing and shaking hands with others....

Another female respondent (32 mpt, P 2) explained her family support in maintaining her hygiene:

During the first few months, they [my family] brought my stylist home to give me haircuts ... they [my family] said that the hair salon was not clean, but now I went there myself, I usually go there when it is less crowded....

Regarding food safety, a respondent (24 mpt, P 15) said:

... That day, I had a yogurt drink, locally made [from raw, unpasteurized milk]... I forgot that I should not have had it.... I remembered when I was in the hospital, my doctor told me such drinks [unpasteurized] made me sick ... now I do not consume any local dairy [from raw, unpasteurized milk] products....

Regarding support at work from colleagues and employers, a female patient ( $84 \mathrm{mpt}, \mathrm{P}$ 12) explained:

I was a teacher, but to have less contact with students, my boss switched my job from teaching to paperwork in the office....
Dietary supplements were commonly administered for the patients to support their diet:

I found that my body was severely weakened in the second year, and also the third year. My diet did not change, I exercised, but I felt weak.... I began to eat multi-vitamin pills with calcium supplement [according to physician order]. After about three weeks, I was feeling much better... (50 mpt, P 8)

Providing support to the patients to take medications on time, especially immunosuppressive agents, was a part of self-care support. The patients and their family members mentioned the importance of this support to adhere to care and treatment. The spouse of a patient said:

Soon after discharge from the hospital, I became responsible for handling medications. If you look at the mobile phone, alarms are set; this assures me that he takes his medications without delay, this is very important.... He has his pills in his handbag, at home, at his daughter's home, it [immunosuppressive medication] is everywhere, which means he would take his pills without any delay even if he forgets his handbag.... (12 month duration of care, P 19)

\section{Discussion}

Self-management requires an active patient's participation to improve care. Self-management is investigated and verified for patients with chronic conditions. ${ }^{17}$ This study addressed the health self-management and self-regulation and self-care related factors affecting adherence to care and treatment. From the perspectives of the participants self-management in adherence to care and treatment was influenced by selfregulation and self-care activities. Beckmann et al defined self-management tasks from the perspectives of liver patients with transplantation and caregivers before and after the surgery as "mastering together the highs and lows", which comprised three core themes as mastering medical management, managing roles together, and managing the highs and lows of emotion. ${ }^{19}$

\section{Self-regulation related factors}

The participants changed their everyday life, regulated their life to deal with their care and treatment. Moilanen defined self-regulation as an ability to adjust one's behavior, attention, emotions and cognitive strategies in response to the stimuli to achieve an aim. ${ }^{24}$ A review of qualitative studies by Kelly et al highlighted the importance of selfregulation in adherence to treatment. ${ }^{25}$ Improving selfregulation contributed to better self-management, ${ }^{26}$ and in patients with diabetes resulted in better adherence to 
treatment. ${ }^{27}$ Self-regulation skills such as self-monitoring are undertaking factors that may clarify the variability of outcomes in current lifestyle obesity treatment interventions. ${ }^{28}$ In this study, self-regulation was encompassed of the patients' efforts in "intentionally changing", "positively thinking", "information seeking", "problem-solving", "past experience transferring", and "self-controlling". Therefore, the patients will be named as self-regulators if they keep on "intentional changing", "positively thinking", "gaining experience", "problem-solving", "generalizing", and "selfcontrolling" in health self-management.

In this study, "intentionally changing" was a factor affecting self-regulation in the patients. The importance of conscious and active changes as a determinant of treatment adherence was highlighted. Intentional changes in the regulation to the daily life changes enable the patient to initiate and continue his/her treatment and care. Moilanen stated that intentional self-regulation was behavior that the individual consciously did in response to changes in attaining a desired behavior or outcome. ${ }^{24}$ Intention identifies the goal-directed reactions to changes leading to goal attainments. ${ }^{29}$

We found that the "positive thinking" was another important factor in self-regulation. Positive thinking can be considered one part of a cognitive type of emotional regulatory strategy, which resets the situation positively. ${ }^{30}$ According to the participants' perspectives, positive thinking corresponded to self-regulation. A positive thinker is able to find happiness, health and a good result in any situation. Through thinking positively, individuals can create thoughts in which they expect achievements and desired outcomes of their treatment and care adherence. Positive thinking could be educated to patients with chronic conditions and effectively encounter worries ${ }^{31}$ and perceived stress. ${ }^{32}$

"Information-seeking" allowed the patients to regulate their everyday life changes. It was an important perceived factor and caused health self-management to adhere to care and treatment. They gained knowledge and skills such as asking questions of health care professional and other patients, paying attention to the social media and involvement in changes. Those patients that look for health information have better health than those who do not seek health information, regardless of information sources. ${ }^{33}$ Patients with a cardiovascular event participating in an expert patient program showed a higher quality of life after 2-year follow-up. ${ }^{34}$

"Problem-solving" could ease everyday life problems in health self-management. Nowadays, problem-solving has a propensity for being taught to chronic patients as an important self-management and life skill. ${ }^{35}$ Problem-solving is a central component of self-management and the key factor of successful individuals and groups in self-management programs ${ }^{36}$ Given that the individuals with the same chronic diseases have similar problems in self-management, problemsolving is considered an element of the educational intervention in the self-management program of chronic diseases. The problem-solving skill has been found as an important factor of self-management in a large and multiracial sample of adults with type 2 diabetes. ${ }^{37}$ In the self-management of chronic disease, problem-solving compromised four components such as problem-solving skill, problem-solving orientation, disease-specific knowledge, and transfer of past experiences. ${ }^{38}$ Similarly, the participants perceived the necessity of transfer of past experiences to the altered health self-management situation. Transferring previous knowledge and skills is a factor related to self-regulation and ultimately the patient's health self-management.

The participants also realized that self-control on fears and stress improved adherence to care and treatment. Similarly, Correia et al reported a direct relationship between self-control and adherence. ${ }^{39}$ Following the transplantation surgery, significant improvements are generally seen in anxiety and depression symptoms. ${ }^{40}$ However, patients may face mental distress and stress ${ }^{41}$ associated with poor adherence. Life-long immunosuppressant therapy, medical monitoring, and the ever-present risk of graft rejection or failure are stress factors. ${ }^{42}$ During the first 6 months after the surgery, patients' quality of life is decreased especially for physical, bodily pain, vitality, social functioning, roleemotional and mental components. ${ }^{43}$ Having self-control enhances happiness through avoiding and dealing with stressful stimuli. ${ }^{44}$

\section{Self-care related factors}

Self-care included any necessary human regulatory action, which was initiated by the patients according to their determinations and under their own control. Self-care skills can be learned and applied to maintain and improve organ and patient's health. In this study, self-care is recognized as a key component in health self-management. The "shift to independence", "vigilance", and "self-care support" are related to self-care activities.

Primary evaluations of self-care promotion programs in patients with rheumatoid arthritis have been reported to be effective. They reduced the need for visits and improved pain control, perceived self-efficacy, and quality of life. ${ }^{45}$ In patients with hypertension, self-care led to the incorporation of complementary and alternative remedies for blood pressure control. ${ }^{46}$ 
This study showed that efforts on independence and responsibility were considered important in the self-care dimension that was considered one of the key components of high-quality health care. In most studies on adolescence and adolescents' transitions into adulthood, separation and independence in receiving medications were emphasized in the process of adherence. ${ }^{47,48}$ Independence can be related to family members or the health care team. ${ }^{49}$ Self-care is an everyday responsibility that can improve the patient's health. ${ }^{50}$

Another finding of this study was vigilance. Patients are more sensitive to their health and seriously follow preventive and care practices due to their susceptibility to risks according to the study by Moonaghi et al. ${ }^{51}$

Self-care support is a key factor in health self-management. It defines that patients, family members, colleagues, and professionals try to support patients and meet their life needs. This finding has been supported by Miller and DiMatteo in diabetic patients, ${ }^{52}$ Prihodova et al in patients with kidney diseases ${ }^{53}$ and Lee Mortensen and Rasmussen in patients with multiple sclerosis. ${ }^{54}$

Self-care constituted a wide range of activities including different levels of hygiene; personal, interpersonal, and environmental based on available recourses.

The findings of this study on health self-management are supported by Redman, ${ }^{17}$ Lorig and Holman,,${ }^{55}$ and Hoffman ${ }^{56}$ indicating self-control, empowerment, self-confidence, management of negative emotions, maintain social roles for life-long care. Also, Richard and Shea clarified that the self-management included self-care, self-monitoring, health behavior change, patient education, collaborative care, and adherence. ${ }^{57}$

\section{Limitations}

The scarcity of studies on adherence to treatment and care in patients with liver transplantation in Iran hindered the comparison of findings and influenced the generalizability of findings to other contexts.

\section{Conclusion}

The patients perceived that health self-management in adherence to care and treatment was a set of factors related to the "self-regulation" and "self-care" behaviors. "Selfregulation" balances new life and "self-care" maintains and improves health. These factors improve health selfmanagement capabilities in patients and improve adherence. This urges the treatment and nursing teams to introduce methods to improve and incorporate this capability into patient care and enable them to overcome challenges in post-transplantation care.

\section{Acknowledgments}

The authors should like to thank all the patients and their families who enthusiastically took part in this study, as well as the liver transplant team, Liver Transplant Commission, and the Liver Clinic staff for their cooperation. This study is based on a Ph.D dissertation in Nursing at the School of Nursing and Midwifery founded by Vice-Chancellor in Research and Technology in the Hamadan University of Medical Sciences, Hamadan, Iran.

\section{Author contributions}

All authors contributed to data analysis, drafting or revising the article, gave final approval of the version to be published, and agree to be accountable for all aspects of the work.

\section{Disclosure}

The authors report no conflicts of interest in this work.

\section{References}

1. Farkas S, Hackl C, Schlitt HJ. Overview of the indications and contraindications for liver transplantation. Cold Spring Harb Perspect Med. 2014;4(5):a015602.

2. Kim WR, Stock PG, Smith JM, et al. OPTN/SRTR 2011 Annual data report: liver. Am J Transplant. 2013;13(S1):73-102.

3. Oliveira RA, Turrini RNT, Poveda VB. Adherence to immunosuppressive therapy following liver transplantation: an integrative review. Rev Lat Am Enfermagem. 2016;24:e2778.

4. Lobiondo-Wood G, Bernier-Henn M, Williams L. Impact of the child's liver transplant on the family: maternal perspective. Pediatr Nurs. 1991;18(5):461-466.

5. Germani G, Lazzaro S, Gnoato F, et al. Nonadherent behaviors after solid organ transplantation. Transplant Proc. 2011;43(1):318-323.

6. Bethany JF, Ahna L. Adherence in adolescent and young adult kidney transplant recipients. Open Urol Nephrol J. 2014;7(1):133-143.

7. Stilley CS, Dimartini AF, de Vera ME, et al. Individual and environmental correlates and predictors of early adherence and outcomes after liver transplantation. Prog Transplant. 2010;20(1):58-66.

8. Lieber SR, Volk ML. Non-adherence and graft failure in adult liver transplant recipients. Dig Dis Sci. 2013;58(3):824-834.

9. Serper M, Van Wagner L, Kang R, Hohmann S, Olthoff K. Burden of readmission following liver transplantation: results from US academic medical centers. Am J Transplant. 2014;14:832.

10. Dharancy S, Giral M, Tetaz R, Fatras M, Dubel L, Pageaux GP. Adherence with immunosuppressive treatment after transplantation: results from the French trial PREDICT. Clin Transplant. 2012;26(3): E293-E299.

11. Fishman JA, Rubin RH. Infection in organ-transplant recipients. NEngl J Med. 1998;338(24):1741-1751.

12. Houle N, Bohannon RW, Frigon L, Maljanian R, Nieszczezewski J. Health promoting behaviors, quality of life, and hospital resource utilization of patients receiving kidney transplants. Nephrol Nurs $J$. 2002;29(1):35-44.

13. Marcelino CA, Díaz LJ, da Cruz DM. The effectiveness of interventions in managing treatment adherence in adult heart transplant patients: a systematic review. JBI Database System Rev Implement Rep. 2015;13(9):279-308.

14. World Health Organization. Adherence to Long-Term Therapies: Evidence for Action. Geneva: World Health Organization; 2003. Available from: http://www.who.int/chp/knowledge/publications/ adherence_report/en/. Accessed November 1, 2018. 
15. Ownby RL. Medication adherence and cognition. Medical, personal and economic factors influence level of adherence in older adults. Geriatrics. 2006;61(2):30.

16. Wang C, Wang G, Yi H, et al. Symptom experienced three years after liver transplantation under immunosuppression in adults. PLoS One. 2013;8(11):e80584.

17. Redman BK. Patient adherence or patient self-management in transplantation: an ethical analysis. Prog Transplant. 2009;19(1):90-94.

18. Ruiz S, Brady TJ, Glasgow RE, Birkel R, Spafford M. Chronic condition self-management surveillance: what is and what should be measured? Prev Chronic Dis. 2014;11:E103.

19. Beckmann S, Künzler-Heule P, Biotti B, Spirig R. Mastering together the highs and lows: patients' and caregivers' perceptions of selfmanagement in the course of liver transplantation. Prog Transplant. 2016;26(3):215-223.

20. Schmid-Mohler G, Schäfer-Keller P, Frei A, Fehr T, Spirig R. A mixedmethod study to explore patients' perspective of self-management tasks in the early phase after kidney transplant. Prog Transplant. 2014; 24(1):8-18.

21. Institute of Medicine (US) Committee on the Crossing the Quality Chasm: Next Steps Toward a New Health Care System. The 1st Annual Crossing the Quality Chasm Summit: A Focus on Communities. Adams K, Greiner AC, Corrigan JM, editors. Washington (DC): National Academies Press; 2004.

22. Malek Hosseini SA, Nikeghbalian S, Salahi H, et al. Evolution of liver transplantation program in Shiraz, Iran. Hepat Mon. 2017;17(11):e60745.

23. Elo S, Kyngäs H. The qualitative content analysis process. J Adv Nurs. 2008;62(1):107-115

24. Moilanen KL. The adolescent self-regulatory inventory: The development and validation of a questionnaire of short-term and long-term self-regulation. J Youth Adolesc. 2007;36(6):835-848.

25. Kelly M, McCarthy S, Sahm LJ. Knowledge, attitudes and beliefs of patients and carers regarding medication adherence: a review of qualitative literature. Eur J Clin Pharmacol. 2014;70(12):1423-1431.

26. Adams RJ. Improving health outcomes with better patient understanding and education. Risk Manag Healthc Policy. 2010;3:61.

27. Shalev I, Geffken GR. Use of self-regulation principles to improve adolescent treatment adherence to the medical regimen for diabetes. J Psychother Integr. 2016;26(4):366-377.

28. Teixeira PJ, Carraça EV, Marques MM, et al. Successful behavior change in obesity interventions in adults: a systematic review of selfregulation mediators. BMC Med. 2015;13(1):84.

29. Gollwitzer PM. Implementation intentions: Strong effects of simple plans. Am Psychol. 1999;54(7):493-503.

30. McCarthy R. The price you pay for the drug not taken. Bus Health. 1998; 16(10):27.

31. Eagleson C, Hayes S, Mathews A, Perman G, Hirsch CR. The power of positive thinking: Pathological worry is reduced by thought replacement in generalized anxiety disorder. Behav Res Ther. 2016;78:13-18.

32. Roodbari O, Zare H, Saeedi H, Divsalar K, Eslamian F. The effectiveness of positive thinking training on perceived stress and happiness in patients with thalassemia major. Rep Health Care. 2015;1(3):88-91.

33. Feinberg I, Greenberg D, Frijters J. Understanding health information seeking behaviors of adults with low literacy, numeracy, and problem solving skills: Results from the 2012 US PIAAC study. Available from: https://static1. squarespace.com/static/51bb74b8e4b0139570ddf020/t/54da7889e4b004 762df45b52/1423603849970/Feinberg_Greenberg_Frijters_PIAAC.pdf, Accessed May 8, 2018.

34. Vega G, Ruíz T, Ruiz V, Lázaro C, Marin C. Long-term results of the expert patients program in patients with cardiovascular disease: a cohort study. J Community Med Health Educ. 2017;7(512):2161-2711.

35. Schumann KP, Sutherland JA, Majid HM, Hill-Briggs F. Evidencebased behavioral treatments for diabetes: problem-solving therapy. Diabetes Spectrum. 2011;24(2):64-69.

36. Funnell MM. Peer-based behavioural strategies to improve chronic disease self-management and clinical outcomes: evidence, logistics, evaluation considerations and needs for future research. Fam Pract. 2010; 27(Suppl 1):i17-i22.
37. Lorig K, Ritter PL, Pifer C, Werner P. Effectiveness of the chronic disease self-management program for persons with a serious mental illness: a translation study. Community Ment Health J. 2014;50(1): 96-103.

38. Hill-Briggs F. Problem solving in diabetes self-management: a model of chronic illness self-management behavior. Ann Behav Med. 2003; 25(3):182-193.

39. Telles-Correia D, Barbosa A, Mega I, Monteiro E. Psychosocial predictors of adherence after liver transplant in a single transplant center in Portugal. Prog Transplant. 2012;22(1):91-94.

40. Pegum N, Connor JP, Young RM, Feeney GF. Psychosocial functioning in patients with alcohol-related liver disease post liver transplantation. Addict Behav. 2015;45:70-73.

41. Baranyi A, Krauseneck T, Rothenhäusler HB. Overall mental distress and health-related quality of life after solid-organ transplantation: results from a retrospective follow-up study. Health Qual Life Outcomes. 2013;11(1):15

42. Potts SG, Masterton G. Transplant psychiatry. J R Coll Physicians Edinb. 2009;39(4):331-336.

43. Jin S, Xiang B, Zhong L, et al. Quality of life and psychological distress of adult recipients after living donor liver transplantation. Transplant Proc. 2013;45(1):281-285.

44. Hofmann W, Luhmann M, Fisher RR, Vohs KD, Baumeister RF, Yes BRF. Yes, but are they happy? Effects of trait self-control on affective well-being and life satisfaction. J Pers. 2014;82(4):265-277.

45. Lorig KR, Mazonson PD, Holman HR. Evidence suggesting that health education for self-management in patients with chronic arthritis has sustained health benefits while reducing health care costs. Arthritis Rheum. 1993;36(4):439-446.

46. Gohar F, Greenfield SM, Beevers DG, Lip GY, Jolly K. Self-care and adherence to medication: a survey in the hypertension outpatient clinic. BMC Complement Altern Med. 2008;8(1):4.

47. Psihogios AM, Kolbuck V, Holmbeck GN. Condition self-management in pediatric spina bifida: a longitudinal investigation of medical adherence, responsibility-sharing, and independence skills. J Pediatr Psychol. 2015;40(8):790-803.

48. Fredericks EM, Dore-Stites D, Well A, et al. Assessment of transition readiness skills and adherence in pediatric liver transplant recipients. Pediatr Transplant. 2010;14(8):944-953.

49. Annunziato RA, Emre S, Shneider BL, et al. Transitioning health care responsibility from caregivers to patient: a pilot study aiming to facilitate medication adherence during this process. Pediatr Transplant. 2008;12(3):309-315.

50. Lorig KR, Sobel DS, Stewart AL, et al. Evidence suggesting that a chronic disease self-management program can improve health status while reducing hospitalization: a randomized trial. Med Care. 1999;37(1): $5-14$.

51. Karimi Moonaghi H, Namdar Areshtanab H, Jouybari L, Arshadi Bostanabad M, McDonald H. Facilitators and barriers of adaptation to diabetes: experiences of Iranian patients. J Diabetes Metab Disord. 2014;13(1): 17

52. Miller TA, DiMatteo MR. Importance of family/social support and impact on adherence to diabetic therapy. Diabetes Metab Syndr Obes. 2013;6:421.

53. Prihodova L, Nagyova I, Rosenberger J, et al. Adherence in patients in the first year after kidney transplantation and its impact on graft loss and mortality: a cross-sectional and prospective study. J Adv Nurs. 2014; 70(12):2871-2883.

54. Lee Mortensen G, Rasmussen PV. The impact of quality of life on treatment preferences in multiple sclerosis patients. Patient Prefer Adherence. 2017;11:1789-1796.

55. Lorig KR, Holman HR. History self-management education: definition, outcomes, and mechanisms. Ann Behav Med. 2003;26(1):1-7.

56. Hoffman AJ. Enhancing self-efficacy for optimized patient outcomes through the theory of symptom self-management. Cancer Nurs. 2013; 36(1):E16-E26.

57. Richard AA, Shea K. Delineation of self-care and associated concepts. J Nurs Scholarsh. 2011;43(3):264. 
Patient Preference and Adherence

Dovepress

\section{Publish your work in this journal}

Patient Preference and Adherence is an international, peer-reviewed, open access journal that focuses on the growing importance of patient preference and adherence throughout the therapeutic continuum. Patient satisfaction, acceptability, quality of life, compliance, persistence and their role in developing new therapeutic modalities and compounds to optimize

clinical outcomes for existing disease states are major areas of interest for the journal. This journal has been accepted for indexing on PubMed Central. The manuscript management system is completely online and includes a very quick and fair peer-review system, which is all easy to use. Visit http://www. dovepress.com/testimonials.php to read real quotes from published authors.

Submit your manuscript here: http://www.dovepress.com/patient-preference-and-adherence-journal 